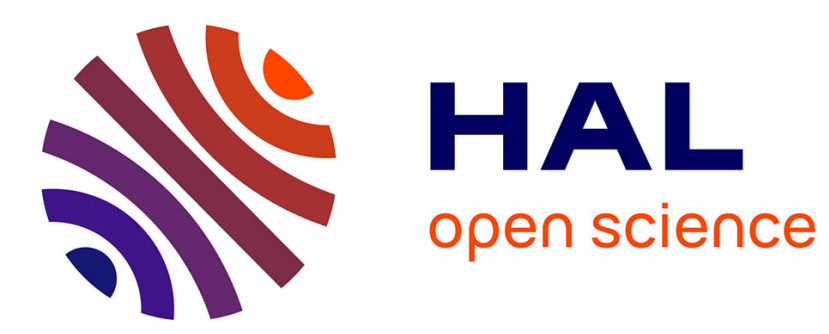

\title{
INTERGRANULAR SEGREGATION OF BISMUTH IN COPPER BICRYSTALS
}

\author{
A. Fraczkiewicz, M. Biscondi
}

\section{To cite this version:}

A. Fraczkiewicz, M. Biscondi. INTERGRANULAR SEGREGATION OF BISMUTH IN COPPER BICRYSTALS. Journal de Physique Colloques, 1985, 46 (C4), pp.C4-497-C4-503. 10.1051/jphyscol:1985455 . jpa-00224706

\section{HAL Id: jpa-00224706 https://hal.science/jpa-00224706}

Submitted on 1 Jan 1985

HAL is a multi-disciplinary open access archive for the deposit and dissemination of scientific research documents, whether they are published or not. The documents may come from teaching and research institutions in France or abroad, or from public or private research centers.
L'archive ouverte pluridisciplinaire HAL, est destinée au dépôt et à la diffusion de documents scientifiques de niveau recherche, publiés ou non, émanant des établissements d'enseignement et de recherche français ou étrangers, des laboratoires publics ou privés. 
Résumé. - On a analysé, par spectrométrie Auger, des joints fracturés "in situ" dans des bicristaux de cuivre, de flexion autour de $\langle 100\rangle$, dopés en bismuth. Pour une désorientation donnée, on précise d'abord certains aspects thermodynamiques et cinétiques de la ségrégation intergranulaire du bismuth. Puis, pour des conditions fixées, on a déterminé comment varie cette ségrégation avec l'angle de désorientation.

Abstract. - In Cu-Bi $\langle 100\rangle$ tilt bicrystals, "in situ" fractured grain boundaries have been analysed by Auger spectrometry. For a given misorientation, certain thermodynamic and kinetic features of segregation have been evaluated. Then, under a given set of conditions, the influence of misorientation angle on grain boundary segregation of $B i$ has been determined,

\section{INTRODUCTION}

Even though the phenomenon of grain boundary segregation has been the subject of many papers, the dependence of intergranular segregation on the grain boundary structure is not well known. Nevertheless, several studies, both direct and indirect, suggest the degree of segregation varies among grain boundaries. The indirect studies were recently reviewed by Balluffi (1). Direct studies of grain boundary segregation by Auger spectroscopy have shown considerable anisotropy of segregation in polycrystals of Cu-Bi (2), as well as in randomly oriented Fe-Si bicrystals. (3). The reported anisotropy has been attributed to the dependence of segregation on grain boundary structure. To examine this effect in detail, segregation studies on oriented bicrystals, in which only one crystallographic parameter varies, are necessary.

In our laboratory, an investigation of oxygen segregation in molybdenum bicrystals was carried out (4). A strong influence of misorientation angle on the segregation level for both $\langle 100\rangle$ and $\langle 110\rangle$ tilt grain boundaries was found. Nevertheless, at present no systematic study of misorientation dependence of grain boundary segregation has been reported. Such a study was the object of the present investigation. There were two principal reasons for the choice of the Cu-Bi system. First, bismuth is known to induce a considerable degree of embrittlement in copper, thereby making it possible to use Auger electron spectroscopy. Secondly, the copper bicrystals with the required characteristics are relatively easy to obtain.

The present paper contains two principal parts. In the first one, we have examined the thermodynamic and kinetic aspects of bismuth segregation in copper. The second part deals with the effect of grain-boundary misorientation on the intergranular segregation of bismuth in $\langle 100\rangle$ tilt bicrystals of copper.

\section{1 - EXPERIMENTAL PROCEDURE}

The copper bicrystals were prepared by the Chalmers method (5) from 99,99\% Cu. 
Bismuth was introduced in the samples by transport in the vapour phase. To achieve this, each bicrystalline sample along with defined quantity of master alloy (containing $0.1 \mathrm{Wt} . \% \mathrm{Bi}$ ) were annealed in sealed evacuated quartz ampoules at $950^{\circ} \mathrm{C}$ for a time calculated from the relation (6): $t=L^{2} / 4 D$, where $L$ is the thickness of the sample and $D=2 \cdot 10^{-8} \mathrm{~cm}^{2} \mathrm{~s}^{-1}$ (7). Subsequently, the samples were quenched in water and the bismuth content was determined by a colorimetric method (8). The heat treatment for segregation was carried out in the temperature range of $400-650^{\circ} \mathrm{C}$.

The samples were fractured and analysed in the chamber of an Auger electron spectrometer ; the incident beam diameter was about $2 \mu \mathrm{m}$, with an energy of $3 \mathrm{KeV}$, and the sample current was low, about $5 \cdot 10^{-3} \mu \mathrm{A}$. Over twenty spots were analysed on each rupture surface. The calculation of surface coverage is questionnable. The Palmberg method (9) defines the surface coverage by bismuth as :

$$
C_{j}(\%)=\frac{\frac{J_{B i}}{n_{B i}}}{\frac{J_{B i}}{n_{B i}}+\frac{J_{C u}}{n_{C u}}} \cdot 100
$$

were $J_{B} i\left(J_{C u}\right)$ is the intensity of Auger peak of $B i$ (Cu). The coefficients $n_{B i}$ and $n_{C u}$, which depend on the characteristics of pure metals Auger spectra, were calculated from data (9). This calculation yields very different values from those obtained by an experimental calibration (10) consisting of the deposition of bismuth onto a previously deposited layer of copper (2). For our experiments, Fig. 1 compares the results given by these methods.

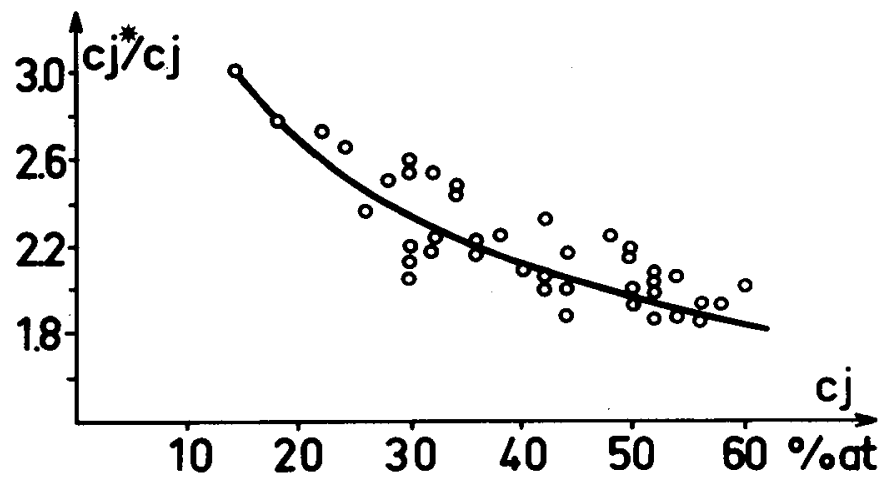

Fig. 1 - Relationship between surface coverage calculated by the Palmberg method $c_{j}$ (9) and by the calibration method of Molinari $c_{j}{ }^{*}(10)$.

In addition, the fractured surfaces were observed in the scanning electron microscope to insure that the fractures were intergranular, as well as to detect the presence of precipitates.

The bismuth concentration measured on one fractured surface presents only a half of its amount at the grain boundary, as the segregant atoms, upon intergranular fracture, are shared among the separating surfaces in average equally (11). Therefore, on the curves presented in this paper, we have twiced the measured bismuth concentrations. Mean $C_{j}$ values (calculated with Palmberg method) and the corresponding $80 \%$ confidence intervals are reported. A strong dispersion of the results for certain grain boundaries is observed. No faceting was observed in the scanning electron microsope but the grain boundary surfaces were not always flat. Therefore a geometrical effect on the Auger spectrometry measurement cannot be excluded, as well as an effect of the grain boundary asymmetry on the segregation level. 
2 - THERMODYNAMIC AND KINETIC ASPECTS OF INTERGRANULAR SEGREGATION IN A GIVEN HIGHANGLE TILT BOUNDARY $\left(30^{\circ}\right.$ AROUND $\left.<100>\right)$

2.1 - Effect of the bulk concentration of bismuth on its intergranular concentra$\underline{\text { tion }}$

In the case of solid solutions at equilibrium at a given temperature, the $c_{j}$ value, as a function of the bulk concentration, increases up to a maximum (saturation) value which is attained for the bulk concentration corresponding to the solubility limit. In our case, the isotherm of segregation at $550^{\circ} \mathrm{C}$, corresponding to a holding of $24 \mathrm{~h}$, shows another relationship (Fig. 2 ). The intergranular concentration increases, reaches a maximum, and then decreases, approaching a value which is about the same as that for a $50 \mu \mathrm{g} / \mathrm{q}$ bulk concentration.

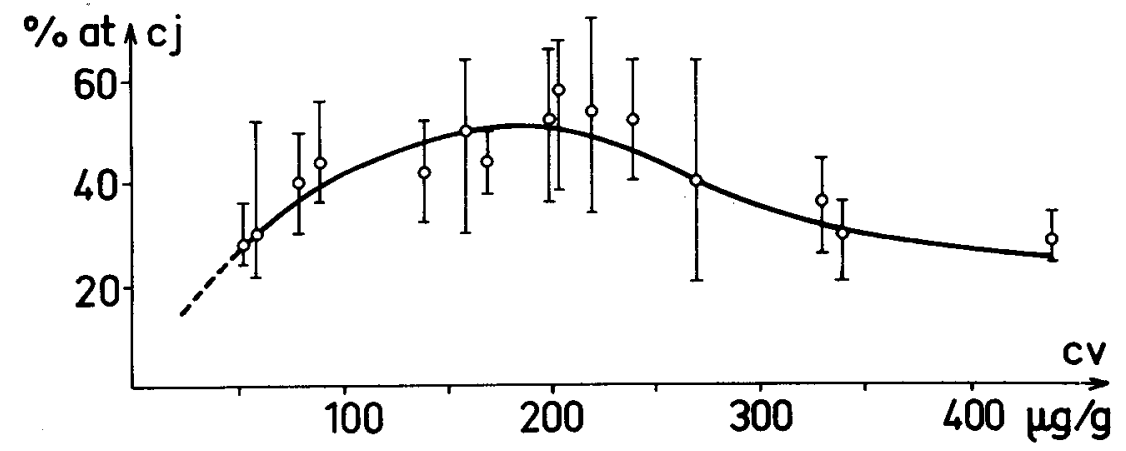

Fig. 2 - Intergranular concentration of $\mathrm{Bi}$, as a function of the bulk concentration. Heat treatment at $550^{\circ} \mathrm{C}$ for $24 \mathrm{~h}$.

Moreover, in the samples with Bi bulk concentrations above $300 \mu \mathrm{g} / \mathrm{g}$, second phase particules were observed on the fracture surface (Fig. 3a). Microprobe analysis revealed the presence of $\mathrm{Cu}$ and a large amount of $\mathrm{Bi}$ in these precipitates, but it was difficult to obtain more information about their composition and structure because of their small size $(\approx 1 \mu \mathrm{m})$.

An interpretation of our experimental curve first requires an estimation of the solubility limit at $550^{\circ} \mathrm{C}$. The data are unclear (12) ; some authors $(13,14)$ find a value of about $150 \mu \mathrm{g} / \mathrm{g}$. Our observations suggest a value of about $50 \mu \mathrm{g} / \mathrm{g}$ at this temperature instead, as is proposed by other authors (15). The curve of Fig. 2 could thus be explained by a kinetic effect. When the bulk concentration $C_{V}$ lies below $50 \mu \mathrm{g} / \mathrm{g}$, the solid solution $\mathrm{Cu}-\mathrm{Bi}$ is at equilibrium and the intergranular concentration increases with $C_{v}$. At about $50 \mu \mathrm{g} / \mathrm{g}$, the limit of solubility is exceeded, but in the range of $50-200 \mu \mathrm{g} / \mathrm{g}$, the alloy remains a supersatured solid solution and $C_{j}$ continues to increase with $C_{v}$. Beyond about $200 \mu \mathrm{g} / \mathrm{g}$, the supersaturation is sufficient for the precipitation of a Bi-rich phase. When $C_{V}$ increases from 200 to $400 \mathrm{\mu g} / \mathrm{g}$, the precipitation reaction progresses and the amount of $\mathrm{Bi}$. decreases both in the solid solution and at the grain boundaries. For the $C_{v}$ values greater than $400 \mu \mathrm{g} / \mathrm{g}$, the supersaturation is sufficient for approximative equilibrium to be reached after $24 \mathrm{~h}$ at $550^{\circ} \mathrm{C}$. The amount of dissolved $\mathrm{Bi}$ in the matrix, as well as the amount of segregated $\mathrm{Bi}$, corresponds to the limit of solubility of this element. 

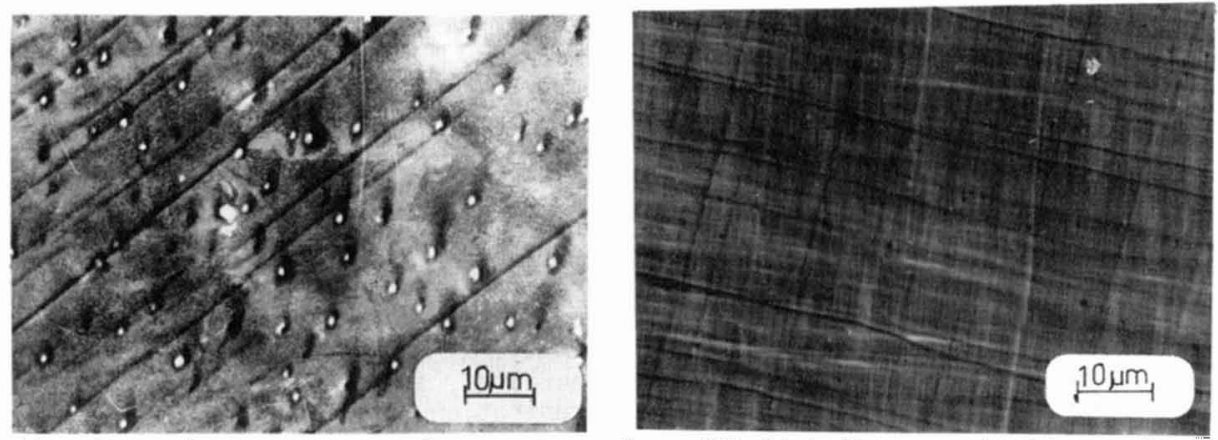

Fig. 3 - Intergranular surfaces of samples with Bi bulk concentrations of : a) $440 \mu \mathrm{g} / \mathrm{g}$, b) $60 \mu \mathrm{g} / \mathrm{g}$.

To the purpose to simplify our study, it would be preferable to investigate equilibrium segregations, and therefore the bulk concentration of $B i$ should be limited to $50 \mu \mathrm{g} / \mathrm{g}$. However, for such low Bi contents, it is impossible to obtain intergranular rupture of the bicrystals in the spectrometer for a sufficiently wide spectrum of misorientations. To avoid this difficulty, we have chosen to examine specimens in a state of supersaturated solution. A study of the kinetics of the segregation process was necessary to select heat treatment conditions, which give a maximum segregation level without the formation of precipitates.

\section{2 - Effect of temperature on intergranular segregation of Bi (Fig. 4).}

No second phase particles were observed on the fractured surfaces in the scanning electron microscope for the studied cases. The heat treatment time was apparently too short to achieve the maximum segregation for temperatures below $500^{\circ} \mathrm{C}$. In the range $500-650^{\circ} \mathrm{C}$, holding of $24 \mathrm{~h}$ seems to be enough to allow for segregation at a level close to the maximum, and too short for the precipitation to start. In this range of temperatures, after $24 \mathrm{~h}$, the grain boundary segregation can be considered to be in temporary equilibrium with the supersaturated solution. As a first approximation, it can be described by the Mc Lean model (15) :

$$
\frac{C_{j}}{1-C_{j}}=\frac{C_{v}}{1-C_{v}} \cdot \exp \left(\frac{E_{s}}{k T}\right),
$$

where $E_{S}$ is the characteristic free energy of segregation at the grain boundary. According to our results, the values of the interaction eneray for an atom of $B i$ at a tilt-boundary misoriented of $30^{\circ}$ around $\langle 100\rangle$ in copper is between 0.68 and $0.73 \mathrm{ev}$. For a comparison with the experiment, the curve corresponding to equation [1] with $E_{\mathrm{S}}=0.7 \mathrm{eV} /$ atom is plotted in Fig.4 as a broken line.

\section{3 - Effect of the time of heat treatment at $500^{\circ} \mathrm{C}$ on the $\mathrm{Bi}$ intergranular segregation}

The results reported in Fig. 5 are consistent with the previous interpretation. In the case under investigation, the segregation process is observed during the first hours. The segregation level reaches a maximum value after about $24 \mathrm{~h}$, an order of magnitude longer than the time observed by other authors (16). The decrease of the intergranular concentration of $\mathrm{Bi}$ with times greater than $24 \mathrm{~h}$ is caused by precipitation. Only in the 10 day annealed samples were intergranular particles of a second phase observed in the scanning electron microscope. 


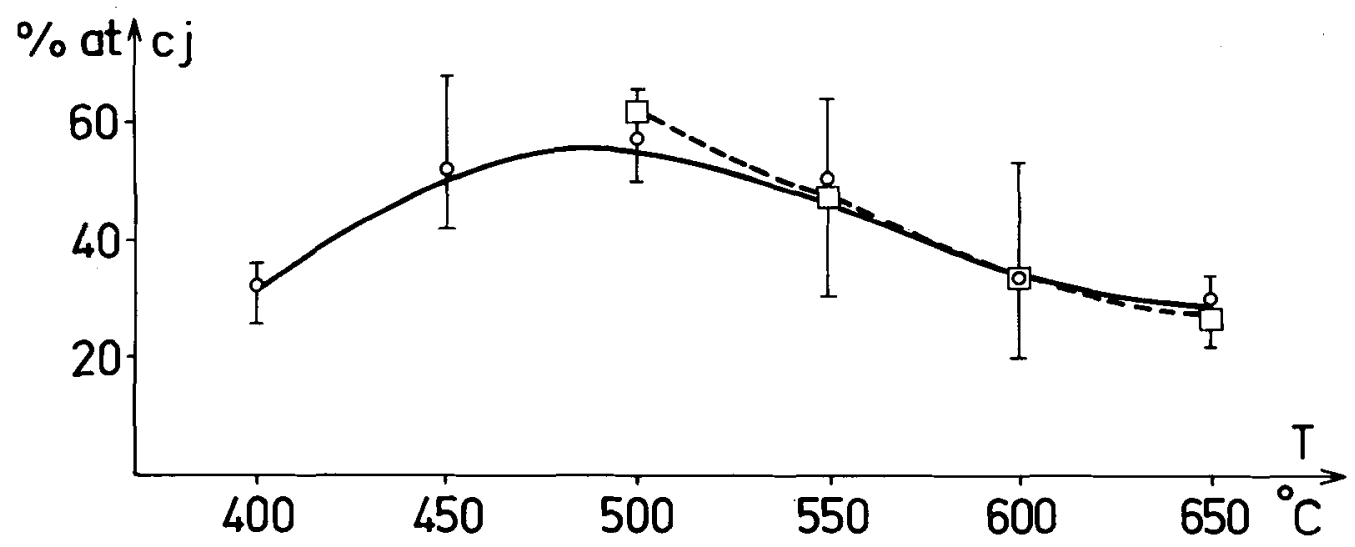

Fig. 4 - Intergranular $B i$ concentration as a function of temperature after $24 \mathrm{~h}$ holding, for $C_{V} \approx 160 \mu \mathrm{g} / \mathrm{g}$.

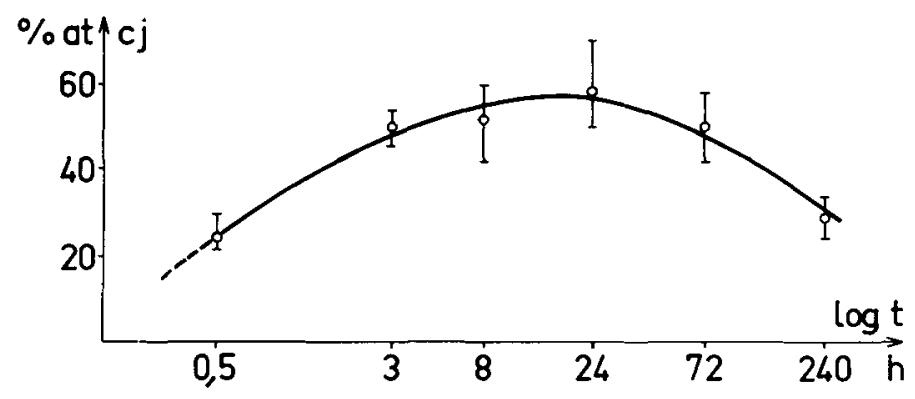

Fig. 5 - Intergranular Bi concentration, as a function of the annealing time at $500^{\circ} \mathrm{C}$, for $C_{V} \approx 160 \mu \mathrm{g} / \mathrm{g}$.

3 - EFFECT OF THE MISORIENTATION ON THE INTERGRANULAR SEGREGATION OF BISMUTH IN COPPER $\langle 100\rangle$ TILT BOUNDARIES

Measurements have been performed on samples with a $120 \mu \mathrm{g} / \mathrm{g} \mathrm{Bi}$ content, annealed at $500^{\circ} \mathrm{C}$ for $24 \mathrm{~h}$. For all misorientations, no intergranular precipitates were observed in the scanning electron microscope. Furthermore, as the segregation kinetics are governed by bulk diffusion, one may consider that intergranular segregation attains its maximal level in all cases after $24 \mathrm{~h}$. Therefore, comparison between different grain boundaries is justified.

In spite of scatter in the experimental results, some conclusions may be drawn (Fig. 6). No intergranular fracture was obtained for the low-angle $\left(10^{\circ}\right.$ and $80^{\circ}$ ) boundaries ; the intergranular concentration of bismuth can be estimated in these cases to be considerably lower than 15 at.\%, i.e., much lower than the intergranular concentration in high-angle boundaries. For the latter, one observes appreciable dependance of segregation on the misorientation angle. Two maxima, the larger $\left(\approx 55\right.$ at. $\%$ ) at about $30^{\circ}$ and the other $\left(\approx 45\right.$ at.\%) at about $60^{\circ}$, as well as a relative minimum $\left(\approx 30\right.$ at.\%) between $37^{\circ}$ and $50^{\circ}$ are found. Abrupt variations in the vicinity of misorientations corresponding to high-coincidence (or low periodi- 
city) boundaries (for example about $37^{\circ}, 53^{\circ}, 67^{\circ}$ ) are not observed, in contrast to the case of sliding in copper $\langle 100\rangle$ tilt bicrystals (17).

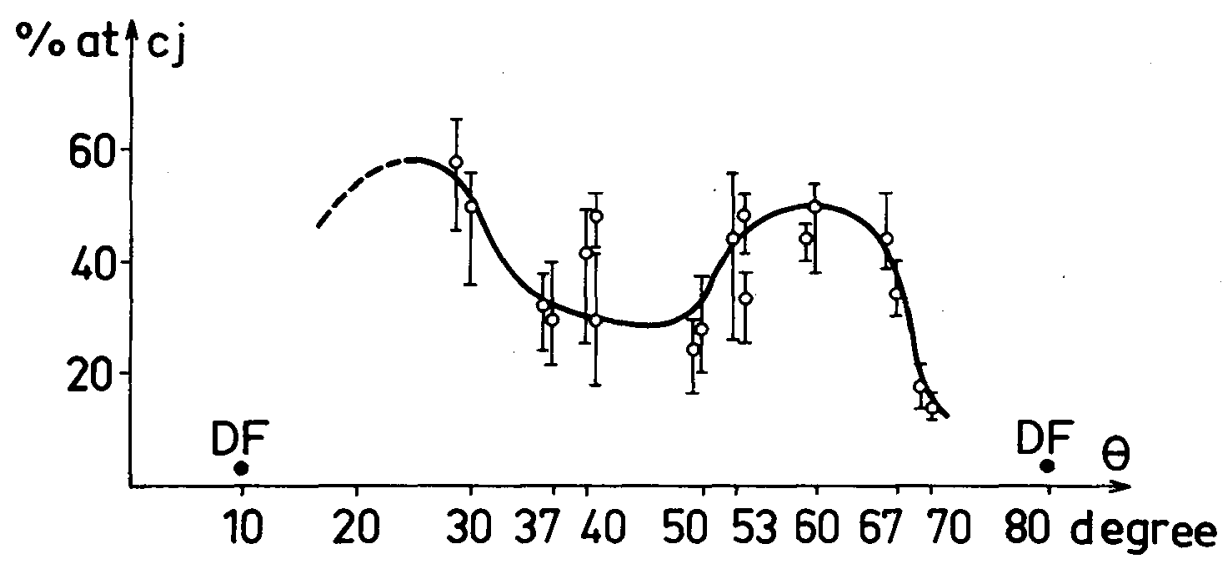

Fig. 6 - Intergranular concentration of bismuth as a function of the misorientation angle for copper $\langle 100\rangle$ tilt bicrystals. Heat treatment at $500^{\circ} \mathrm{C}$ for $24 \mathrm{~h}$, $C_{\mathrm{y}} \approx 120 \mu \mathrm{g} / \mathrm{g}$.

$D F$ : ductile fracture.

For high-angle boundaries, the maximum enrichment factors for $\mathbf{B i}$ that we have measured lay between $4.10^{3}$ and $1.5 .10^{4}$, corresponding to mean segregation energies (deduced from equation [1]) between about 0.55 and $0.7 \mathrm{eV}$. These enrichment factors are not as high as those observed in previous works ( 2 to $5.10^{4}$ ), where a monolayer of $\mathrm{Bi}$ has been found at grain boundaries in copper polycrystals $(2,13,18)$. Therefore, it seems that a tilt grain boundary defined by a misorientation around a dense axis, along which the periodicity of the grain boundary structure is low, allows for a lower segregation than an. entirely random grain boundary.

We can easily understand the reason why the segregation is at a low level for the low-angle boundaries and grows with the misorientation. The adsorption sites are very likely situated along the dislocations which form on such grain boundaries. However, we are not able to give a reliable interpretation of the segregation variation for high-angle boundaries. No correlation with the grain boundary energy exists ; for the type of grain boundary in f.c.c. structures being considered, the energy is almost constant for high-angle misorientations (19). Taking in consideration the large size of bismuth atom, compared to copper atom, we can expect that the intergranular adsorption sites are in tension in the pure metal. Thus, the intergranular formation volume might represent the segregation propensity of the grain boundary. We note there is a likeness between the present results and the variation of the formation volume with misorientation : simulation calculations of structures of the same kind of boundaries in Al (19), show two maxima, at about $20^{\circ}$ and $60^{\circ}$, with a minimum range between $37^{\circ}$ and $53^{\circ}$. Nonetheless, it seems to us that the best way for validly interpreting the connection between segregation and structure is to simulate grain boundary structures in the presence of foreign atoms, in order to obtain the possible adsorption sites and their interaction energies, and the maximum level of segregation. Such studies have begun $(20,21)$ and we intend to undertake such computer simulations.

\section{CONCLUSION}

The knowledge of the connection between the grain boundary structure and segregation is not very extensive. With the use of copper bicrystals, we were able to 
determine the influence of the misorientation on the $B i$ segregation in $C u<100\rangle$ tilt boundaries by Auger electron spectrometry.

Because of the plasticity of copper bicrystals, it is possible to provoke "in situ" intergranular fracture only if the $B i$ intergranular content is more than 10-15 at. \%. To obtain intergranular ruptures in most cases (except for low-angle boundaries), we have studied supersaturated bicrystals with a $\mathrm{Bi}$ content of about $120-150 \mu \mathrm{g} / \mathrm{g}$, even though the limit of solubility has been estimated to be $50 \mu \mathrm{g} / \mathrm{a}$ at about $500^{\circ} \mathrm{C}$. We have shown that the maximum segregation level is attained after an annealing time of $24 \mathrm{~h}$ at $500^{\circ} \mathrm{C}$.

Under these conditions, the enrichment factor of the interqranular bismuth in copper bicrystals is less than $10^{3}$ for small-angle boundaries and between 0.4 and $1.5 .10^{4}$ for misorientations lying in the range 20-70 . For high-angle boundaries we have actually observed significant variations of this factor with the misorientation angle, i.e., with the grain boundary structure. Computer simulations seem to be a promising way to understand the connections between the intergranular structure and segregation. To compare models with experimental results, it is still necessary to obtain more, reliable experimental data, if possible from oriented bicrystals,

\section{REFERENCES}

(1) BALLUFFI R.W., in "Interfacial Segregation" (W.C. JOHNSON and J.M. BLAKELY ed., A.S.M., 1979) p. 193.

(2) POWELL B.D. and WOODRUFF D.P., Phil. Mag. 34 (1976) 169.

(3) WATANABE T., MURAKAMI T. and KARASHIMA S., Scripta Met. 12 (1978) 361.

(4) BROSSE J.-B. and BISCONDI M., Proceedings of the 10th Plansee-Seminar (Reutte, 1981), vol. 2, p. 205 .

(5) BOOS J.-Y., DUOUAIRE B., FAURE F., LEROY F., RANSON C. and RIEU J., Mém. Sci. Rev. Mét. 68 (1971) 443.

(6) DARKEN L.S., in "Atom Movements" (A.S.M. ed., 1951) p. 1.

(7) GORBACHEV V.A., KLOTSMAN S.M., RABOVSKIY YA.A., TALINSKIY V.K, and TIMOFEYEV A.N., Phys. Met. Metall. 44 (1978) 191.

(8) French Standard NF A06-723 (1967).

(9) DAVIS L.E., Mac DONALD N.C., PALMBERG P.W., RIACH G.E. and WEBER R.F., "Handbook of Auger Electron Spectroscopy" (Phys. Electronics Ind. ed, 1976).

(10) MOLINARI C., JOUD J.C., in "Physical Chemistry of the Solid State" (P. Lacombe ed., ELSEVIER, 1984) p. 151.

(11) VIEFHAUS H., MOLLER R., ERHART H., and GRABKE H.J., Scripta Met. 17(1983) 165.

(12) HANSEN M., "Constitution of binary alloys" (Mc Graw-Hill Book Comp. ed.,1958).

(13) HONOROS E.D., 3. Physique, 36 (1975) C4-117.

(14) BASSI G., Z. Metallkunde 48 (1957) 394.

(15) HONDROS E.D. and SEAH M.P., Int. Met. Reviews (1977) 262.

(16) JOHNSON W.C., JOSHI A. and STEIN D.F., Met. Trans. 7A (1976) 949.

(17) LAGARDE P. and BISCONDI M., Mém. Sci. Rev. Mét. 71 (1974) 121.

(18) POWELL B.D. and MYKURA H. Acta Met. 21 (1973) 1151.

(19) BISCONDI M., J. Physique 36 (1975) C4-57.

(20) CHANG H.K., IEE J.K. and STEIN D.F., in "Interatomic potentials and crystalline defects" (J.K. LEE ed., Met. Soc. of AIME, 1981) p. 373.

(21) SUTTON A.P. and VITEK V., Acta Met. 30 (1982) 2011. 